\title{
Current condition of tourism exchange between Taiwan and Hokuriku district and its promotive measure
}

\author{
T. Oyabu ${ }^{1}$, A. Sawada ${ }^{1}$, Z. Zhu ${ }^{1} \&$ A. Ohuchi ${ }^{2}$ \\ ${ }^{1}$ Graduate School of Regional Economic Systems, \\ Kanazawa Seiryo University, Japan \\ ${ }^{2}$ Graduate School of Information Science and Technology, \\ Hokkaido University, Japan
}

\begin{abstract}
Taiwanese tourists visiting the Hokuriku district in Japan are greatly increasing. The Hokuriku district includes Ishikawa, Toyama and northern part of Gifu prefecture (Takayama, Hida cities and Shirakawa village) in this study. The ratio of Taiwanese tourists visiting the district was the largest out of all foreign travelers in 2005. Korean tourists represent the greatest percentage of foreign travelers visiting the whole of Japan. It is necessary to know the factors causing this characteristic. The main factors are the chartered flights that are designed by an old established hotel in the district and PR activities in Taiwan. Fundamentally, the Taiwanese and Japanese express strong interests in their mutual cultures with the deep historical and cultural ties greater than those between the Chinese and Koreans. It is necessary to develop the interesting tourism resources for the Taiwanese and go ahead with tourism exchange continuously. In this study, the effective measures to increase Taiwanese travelers are mentioned. Interesting resources in the Hokuriku district for Taiwanese are the landscapes, the snow and the Japanese type of spa. It will be effective to develop the tourism route linking the snow and the spa. The majority of Taiwanese travelers are in tour groups. It is important to develop the system for promotion to independent travelers.

Keywords: tourism resource, Hokuriku district, data analysis, travelers, tourism exchange.
\end{abstract}




\section{Introduction}

The number of foreign tourists visiting Japan is currently increasing. The number comes to about 500-700 thousands per month. This achievement is largely dependent on the Visit Japan Campaign (VJC). VJC was proposed by the Japanese government in 2003. Korean tourists are most populous out of foreign visitors to Japan. The number was 1.75 millions in 2005 and the rate was $26 \%$. Taiwanese visitors represent about 1.3 million (19\%) and American visitors represent 0.83 million (12.3\%). The increasing rate of Taiwanese inbounds went up $17 \%$ in 2005 . This means that the Taiwan-Japan tourism exchange is becoming increasingly important [1]. The ratio of Taiwanese tourists that visited the Hokuriku district was the largest out of all foreign travelers in 2005. The Hokuriku district includes Ishikawa, Toyama and the northern part of Gifu prefecture (Takayama, Hida cities and Shirakawa village) in this study. Tourism campaigns were implemented in Taiwan by the Toyama and Ishikawa prefectural policies in 2004 and 2005. The chartered flights (over 70 between Taiwan and Komatsu and Noto airports, which are designed by an old established hotel (Kaga-ya)) in the district were held and various kinds of PR activities were also held in Taiwan. These matters worked well to increase Taiwanese guests [2].

In the Hokuriku district, inbound tourism has decreased remarkably since 1992. A slow decline in inbounds is also expected in the coming five years. It is fundamental to propose a policy of increasing foreign visitors and conducting an active exchange with a view to internationalization. The Taiwanese have a relative sense of closeness to the Japanese and the culture, and they hope to encourage them to visit [3]. It is necessary to utilize these effective features in tourism exchange between both countries. The population of Taiwan was about 22.75 million and GDP was 290 billion US dollars in 2004. The foreign currency reserves of Taiwan are in fourth position, the top is China and the second is Japan. Russia is third. The land area is nearly equal to Kyusyu and most Taiwanese are Han people. The rest are native [4,5]. Taiwan had diplomatic ties with only 26 countries in 2005 . This restricts the internationalization of Taiwan. Considering the economic potential, the Taiwanese can visit Japan moreover, for example the Hokuriku district. It is necessary to propose measures for the Taiwanese in terms of hardware and software [6].

In this study, the trend of Taiwanese visitors to the Hokuriku district was examined. Mr. Yoichi Hatta (1886-1942) contributed to the agricultural recovery in Taiwan. He was born in Kanazawa city in the Ishikawa prefecture. The Taiwanese are yearning for him even now. The trends in the following tourism spots and cities are mainly examined in this paper, namely Kenrokuen Garden (Kanazawa city), Tateyama-Kurobe Alpine Route (Toyama pref.), Takayama city and Shirakawa Village. A lot of Taiwanese are visiting the cities. The attractive tourism resources for Taiwanese were also examined and the driving measures for tourism exchanges between Taiwan and the Hokuriku district are reported. As for the results, snow (landscape and experience), cherry blossom, street and beautiful nature centering on hot-spring resorts are effective. It is 
better to open money exchange counters for the Taiwan dollar (NT dollar), massmarket discounters of appliances and one-hundred-yen shops.

\section{Kenrokuen Garden}

Kenrokuen Garden is one of the big three gardens in Japan and is located in Kanazawa city. Kanazawa city is in Ishikawa prefecture in which there are various types of tourism resources. Many tourists visit the prefecture year-round. In the prefecture, there are primarily Kanazawa, Nanao, Wajima, Komatsu, Hakusan and Kaga cities. The population of Kanazawa city is about 0.45 million and the number of households is 183 thousand. The GDP is 17.4 billion US dollars and the inbounds are about 6 million. The inbounds throughout Ishikawa prefecture were about 20.4 million in 2005. The number of lodgers reaches 2.1 million. It accounts for a third of inbounds. Foreign lodgers were about 110 thousand, which accounts for 5\% of all lodgers. Foreign visitors to Kenrokuen Garden were about 75 thousand in 2005. Most of them visited Kanazawa Castle simultaneously. It is located near Kenrokuen Garden. Of foreign tourists who visited Kanazawa, almost $68 \%$ visited Kenrokuen Garden. The number of annual lodgers from districts and countries is as follows; Taiwanese was 65 thousand, Korean was 13 thousand, American was 10 thousand, Chinese was 2.2 thousand and Hong Kong was 0.8 thousand in 2005. The inbound growth rate of Taiwanese to Hokuriku was the highest. The number of visitors from other countries remains roughly flat. Many of the tourists that visited Hokuriku also visited big cities (Tokyo, Osaka or Nagoya). There are various tourism spots in the Hokuriku district, namely Kenrokuen Garden, Wakura Spa, Kaga Spa, Tateyama-Kurobe Alpine Route and Shirakawa-go, which is a World Heritage site. These spots and some tourism experiences can be amalgamated. The number of lodgers in Kaga-ya, which was the best Japanese-style hotel, reached 18.5 thousand in 2005 .

The change of monthly inbounds to Kanazawa city is shown in Fig.1. The data were examined in 2004 and stayed about the same in 2005. There are many inbounds in August and relatively many inbounds in April, May, October and November. There are a small number of visitors in December-March, namely the cold season. In the season, it is difficult to come into contact with a local culture in the Hokuriku district but the representative winter dishes taste very good. They are Echizen-Crab and fish. It is necessary to launch a public relation campaign for the spa and frequent snow in winter. The change in foreign visitors to Kenrokuen Garden is shown in Fig 2. The plots for Taiwanese, Korean, American and Chinese in 2005 are also indicated in the figure. The pictures of Kanazawa Castle and Kenrokuen Garden, which are the representative tourism resources in Kanazawa, are shown in Fig.3. The resources abut each other. Kanazawa Castle was built in 1583 under advisement of Ukon Takayama, who was the Christian feudal lord and Toshiie Maeda entered the castle. Kenrokuen Garden is a representative feudal-load garden from the Edo period. There is Seisonkaku just south of the garden. It was built by the 13th Kanazawa load in 1863. It was a retreat of the Lady of 12 th load. It is also a very interesting 
building from a historical angle. It is necessary to describe the attractiveness of Kanazawa with the historical background.

There are many accumulated unique cultures from the Edo period in Kanazawa and many historical tourism resources still remain undamaged by war. There are Noh, Kaga printed silk, tea ceremonies and Kutani ware as traditional cultures. Noh is a traditional masked dance-drama. There is Higashi-Chaya-gai as an interesting tourism resource, which is an old street in Kanazawa city. It is thought that these resources are attractive to Taiwanese tourists.
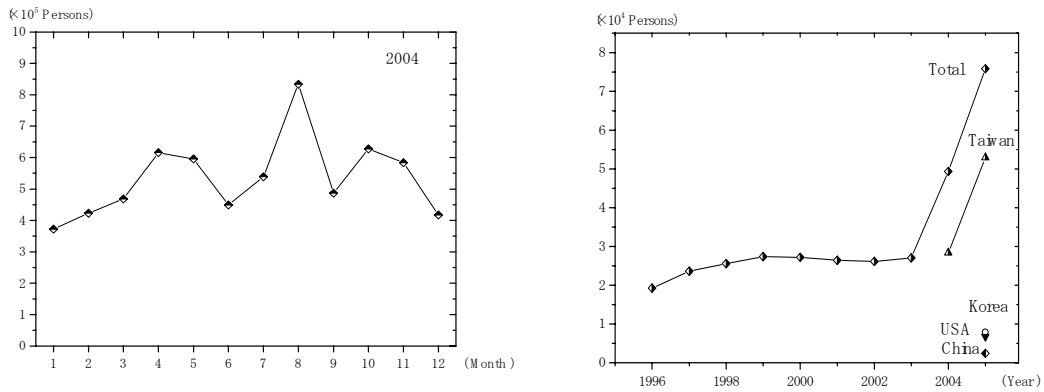

Figure 1: $\quad$ Number of monthly visitors to Kanazawa city.

Figure 2: Number of foreign visitors to Kenrokuen Garden.

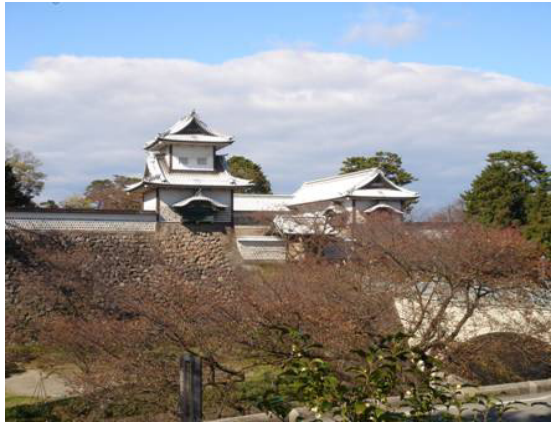

(a) Kanazawa Castle

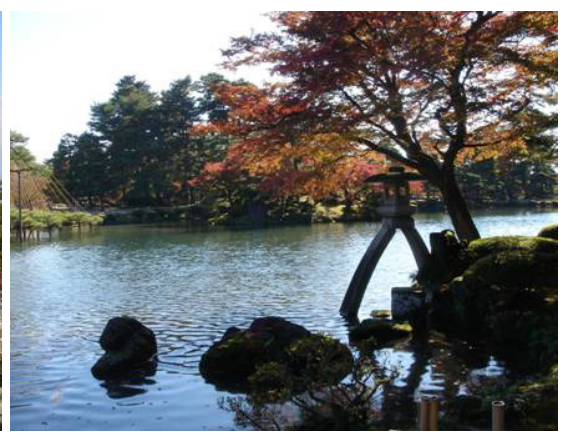

(b) Kenrokuen Garden

Figure 3: Photographs of Kanazawa Castle and Kenrokuen Garden.

\section{Tateyama-Kurobe Alpine Route}

There are many tourism resources in the Toyama prefecture. The main four resources are as follows: Tateyama-Kurobe Alpine Route, Unazuki Spa, OwaraKaze-no-Bon and Zuiryuji (nationally important cultural property). Owara-Kazeno-Bon is a Bon festival dance. Zuiryuji is a temple. It was wholly opened in 1971. Mt. Tateyama belongs to Chubu-Sangaku national park and is a representative mountain called North Alps in Japan. The height is about 3,000 m. 
Almost all climbers long to climb the mountain. It is said that the mountain was opened by an Eccyu-keeper (Mr. Saeki) in the Kamakura period. The general route to visit is as follows:

Toyama station $(\mathrm{JR}) \rightarrow$ Tateyama station $\rightarrow$ Bijyo-daira $\rightarrow$ Midagahara $\rightarrow$ Murodo $\rightarrow$ Daikanbo $\rightarrow$ Kurobe-daira $\rightarrow$ Kurobe-lake $\rightarrow$ Kurobe-dam $\rightarrow$ Ogisawa $\rightarrow$ Shinano-omachi (JR station)

The reverse route can be also adopted. The communications to travel the circular trip are as follows: train, cable car, bus, trolley and cableway. We can aim for the top of Mt. Tateyama (3,015 m) from Murodo $(2,450 \mathrm{~m})$ on foot. The mountain is closed in winter. It has hail and remaining snow even in summer. Visitors can have a precious experience. Many tourists visit the route during "Golden Week", namely from the end of April to the beginning of May. The snow remains and the big snow wall (height is about $20 \mathrm{~m}$ ) arises. The wall is called "Yuki-no-Otani" which is televised every year. Many Taiwanese tourists visit the route. The change of visitors to the route is shown in Fig. 4. It is fluctuating and decreasing. The change for foreign visitor from 2003-2005 is indicated in Fig.5. Taiwanese visitors are increasing linearly and considerably. The change of monthly foreign visitors for April of 2005 to April of 2006 is shown in Fig. 6. The route is closed from December to March. There are a great number of visitors during "Golden Week". This tendency is the same for the Japanese. If many foreign tourists visit the route from June to November, it is an important improvement for effective utilization of this facility. The number of visitors is largely dependent upon the weather. The picture of "Yuki-no-Otani" is shown in Fig. 7.

Many tourists also visit Unazuki Spa, which is located in the east of Toyama prefecture. The number of lodgers in 2005 was about 400 thousand and the number of day-trippers was about 60 thousand. Most visitors stay at a hotel. The number of foreign inbounds was only about five thousand (Korean $60 \%$, Taiwanese $30 \%$ ). The number of Korean visitors is twice that of Taiwanese visitors, according to the PR of tour companies. This characteristic differs from

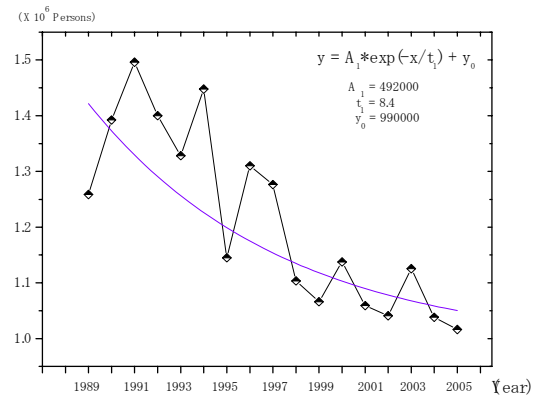

Figure 4: $\quad$ Change in visitors to the Tateyama-Kurobe Alpine Route.

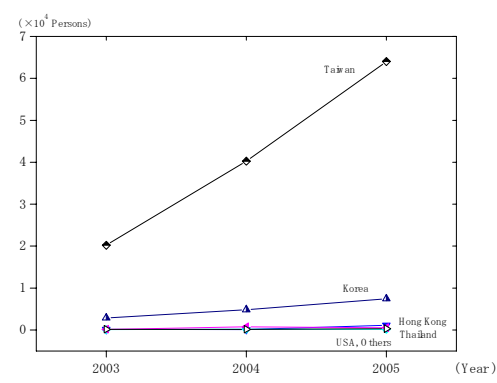

Figure 5: Number of foreign visitors to the alpine route in 2003-2005. 


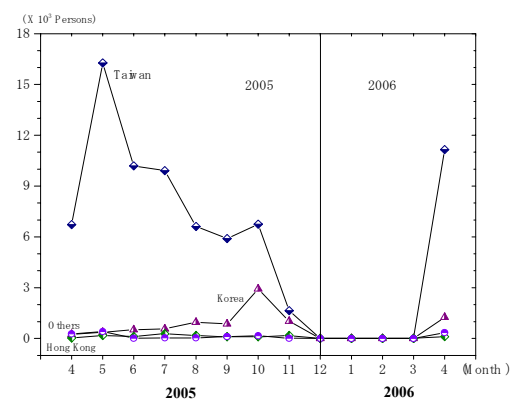

Figure 6: Number of monthly visitors to the route in 2005-2006.

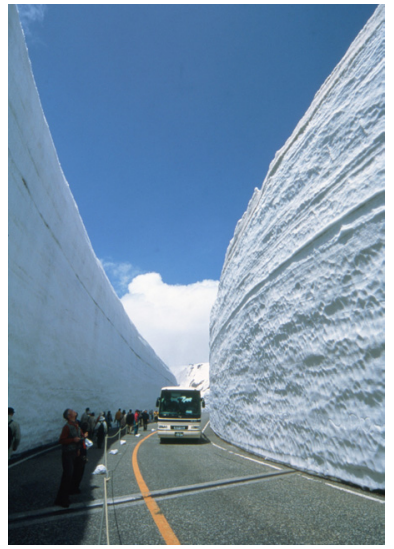

Figure 7: Photograph of Yukino-Otani.

the ones of other areas. The change of monthly foreign inbounds is shown in Fig. 8. There are two peaks in May and October, which is the foliage season. There are small numbers of visitors in December to March.

\section{Takayama City}

There are many interesting remainders of the Jomon Period in Takayama city. Many Japanese find the historical resources quite impressive. The unearthed precious Jomon stone and ware are exhibited in Takayama city. Takayama city is located in the north part of Gifu prefecture, which is composed of the Mino and Hida areas. Takayama belongs to the Hida area. The relationship between Hida and Mino is not so close and there is an economic disparity between the areas. The Hida area originally had active cultural and economical exchanges with Toyama and Ishikawa prefectures. The population and number of households in Takayama city are 96 and 34.2 thousand. The area is about $21,800 \mathrm{~km}^{2}$, which is equal to the Tokyo Metropolis [7]. The city specifically has been focusing on tourism development for nearly a decade and it is now taking effect. It also promotes urban development, namely secure, safe and comfortable urban development, and goes forward to make all the facilities barrier-free. Consequently, handicapped tourists can easily visit the city. Brochures for foreign tourists are expressed in ten languages and many foreign guests visit the city. The inbounds for the city reached to 4.3 million because of the Exposition of Global Harmony (Ai-Chikyu-Haku) in 2005. Foreign lodgers were 90 thousand; equal to the city population. Monthly visitor numbers are shown in Fig. 9. The characteristics for all visitors, lodgers and day-trippers are indicated in the figure. There are many guests in "Golden Week" (April and May), August and October (autumn color of leaves). The countries and regions of the foreign guests are shown in Fig. 10. The Taiwanese are the majority at 52.1\%. Asian 
visitors occupy $61.5 \%$. The guests from Europe and the United States are over $30 \%$ and they have a tendency to visit the regions, which offer a well-cared for living environment, welfare and hospitality. The number of foreign guests is indicated in Fig. 11. The increase in guests from Asia raises the whole of the increase. The city government is adopting policies to prevent the old streets. There are many tourism resources in the city, for example traditional streetscapes, history and culture and scenic areas during every season. The guests from Europe and the United States as well as Asia are satisfied with those resources.

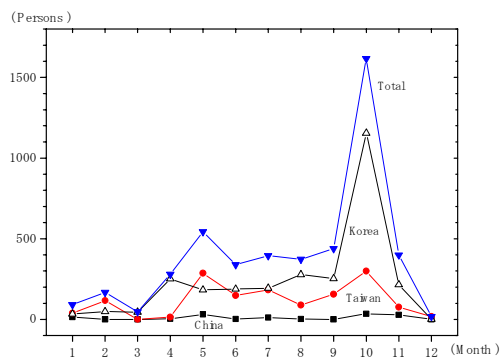

Figure 8: Number of monthly visitors to Unazuki Spa in 2005 .

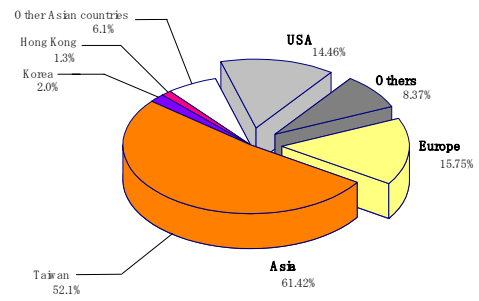

Figure 10: Countries and regions of foreign visitors to Taka-yama city in 2005.

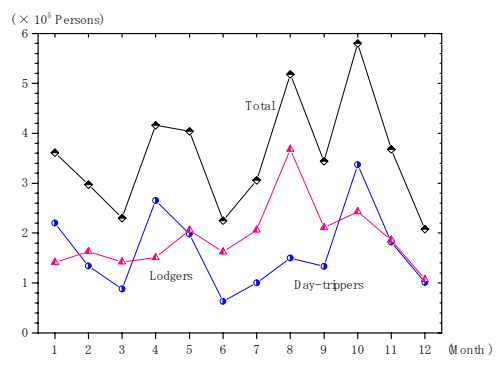

Figure 9: Number of monthly visitors to Takayama city in 2005 .

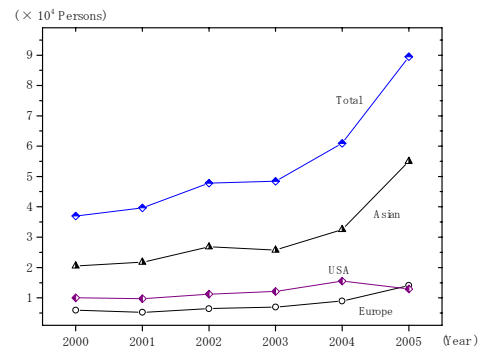

Figure 11: Change of foreign visitors to Takayama city.

\section{Shirakawa Village}

The historic villages of Shirakawa-go and Gokayama were designated as World Heritage sites in 1995 and the number of visitors increased. Shirakawa is located in the north part of the Gifu prefecture and Gokayama is located in the south part of the Toyama prefecture. Both villages are bounded. The current main industry 
in the villages is tourism [8]. It varies from agriculture and forestry. Shirakawago was opened in the 8th century for mountain worship and the fleeing Heike warriors lived there in the last half of the 12th century. The following were mainly produced: Japanese paper, explosives and silk culture as well as agriculture and forestry. The population of Shirakawa Village was 1.9 thousand and number of households was 545 in 2005 [9]. The area is $357 \mathrm{~km}^{2}$. The inbounds were 1.44 million (day-trippers 1.36 million, lodgers 80 thousand). The number of inbounds in 2003 was 1.56 million. It is decreasing. The rate of inbounds for Shirakawa-go and Gokayama was about 7:3. The number of foreign guests was 50 thousand and the Taiwanese accounted for $88 \%$ (44 thousand) of the foreign inbounds, followed by Koreans (1.6 thousand), Americans (950) and Europeans $(1,260)$. Those data were collected by interview survey at auto parks in Shirakawa Village. The change of inbounds for 1989 to 2005 is indicated in Fig. 12. Figure 12(a) shows the change in lodgers and day-trippers. Figure 12(b) shows the scattering diagram for both the data and the coefficient of correlation $(-0.7)$. There is a correlation to some degree and the lodgers decrease when the day-trippers increase. The photograph of the settlement is shown in Fig. 13. It is better to decrease the lodgers in a world-heritage area from the standpoint of environment conservation. It is also necessary to develop the regional and attractive souvenirs. They are not many and most are ordinary.

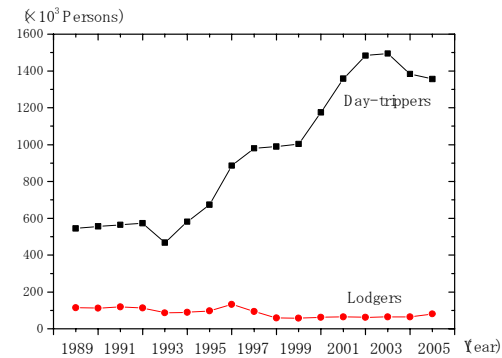

(a) Changes of day-tripper and lodger

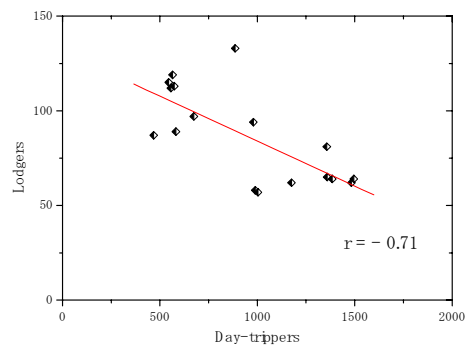

(b) Scattering diagram

Figure 12: Changes of day-trippers and lodgers, and the scattering diagram.

\section{Attractive resources for the Taiwanese}

The GDP per capita in Taiwan exceeds 1.6 million yen and is ranked 6th in Asia. In Asia, Japan is number one followed by Hong Kong, Singapore, Brunei, Macao, Taiwan and Korea. The Taiwanese feel a strong affinity toward Japan in the world and the increase of inbounds is expected. The tourism measures should be constructed with an eye to the Asian Union rather than U.S. and EU. China, Korea, Taiwan, Hong Kong and Japan will become the heart of the Asian Union. It is essential to promote cultural and tourism exchanges among those countries and regions. 


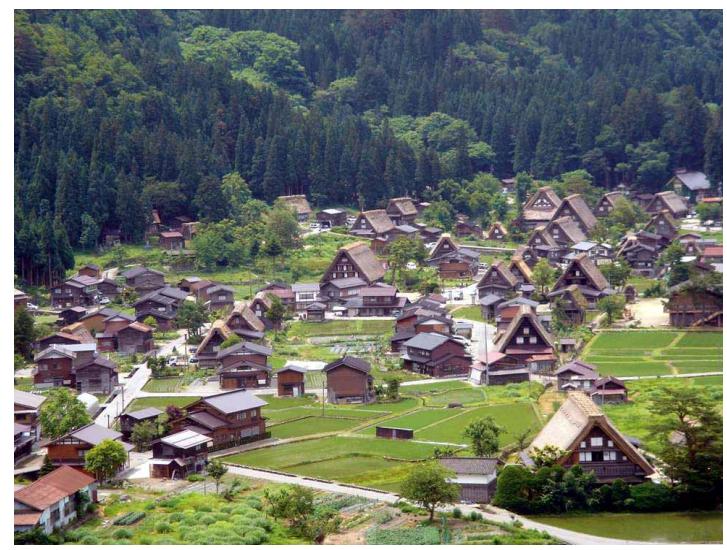

Figure 13: Photograph of Hagi-machi settlement in Shirakawa-go.

The Taiwanese orientation is also changing greatly, namely from city circular trips to country trips and from group tours to personal trips. Package tours have been mainly used in recent years because personal trips are pretty high in cost compared to group tours. The Taiwanese are interested by the magnificent nature such as the Tateyama-Kurobe Alpine Route. The Taiwanese people visiting Japan were fairly evaluated on shopping, lodging and eating. The cost of visiting the Hokuriku district is higher than principal cities such as Tokyo, Yokohama, Osaka and Nagoya. The traveling period for visiting the district is about five days and the cost is about 98,000 yen as an average. It is the highest district in cost out of others in Japan [4]. The cost for Tokyo is about 70,000 yen.

Taiwanese individual trips will increase hereafter and the measures for the trips are necessary. The appeals of the Hokuriku district for the Taiwanese are as follows:

1.hot springs, 2.snow (experience and scenes), 3.magnificent sights (the Chube Mountain National Park etc), 4.old streets (Gasyo-zukuri, Takayama and Furukawa cities, Kanazawa Higashiyama etc), 5.fireworks and yukata (cotton kimono for summer season), cherry blossom, 6.Kenrokuen Garden, shrine and Buddhist temples, 7.the culture of the Chinese character (Kanji) is the same in Taiwan and China.

It is necessary to assimilate those resources into lodging, eating and shopping as the needs of Taiwanese tourists, and propose high value-added travels. It is also wished to establish the one-hundred yen shops, exchangers for the New Taiwan Dollar and discount shops of electric appliances.

\section{Recommending route in Hokuriku District}

The tourism route is different with each season, formation, purpose and cost. The super wealthy visit the destination by their own jet plane and stay at a gorgeous hotel. The meal fee and tip for a server exceeds the limit of common sense. There are not the tourist infrastructures for the super wealthy in the Hokuriku 
district. It is better to develop the recommending routes for the middle classes. The Taiwanese prefer a visiting type than a sojourn, namely they prefer to visit many places. It is desirable to develop the recommending route concerning the following areas. The Tateyama-Kurobe Alpine Route is closed in winter.

(1) Ishikawa prefecture

Wakura Spa, Kenrokuen Garden, Higashi-Cya-ya-Gai, 21st museum, Kaga Spa

(2) Toyama prefecture

Tateyama-Kurobe Alpine Route, Owara-Kaze-no-Bon, Unazuki Spa, fishing for firefly squid

(3) Hida area

Old streets in Takayama and Furukawa, world heritage in Shirakawa-go

It is better to include spas, shopping, old streets, scenery and contact with inhabitants [10]. The tourism formation of the Taiwanese has nearly all been package tours until now. However, personal travel will increase in the future. Therefore, it is fundamental to provide a wide variety of accommodation.

\section{Conclusion}

The trend survey for Taiwanese tourists in the Hokuriku district was carried out. The increase of Taiwanese tourists is significant in the district except in Unazuki Spa. It is thought that Unazuki is missed by the tourism routes in Hokuriku district because the area is located well within the Niigata prefecture. Most Taiwanese tourists enter Japan through Tokyo, Osaka or Nagoya and visit many places by sightseeing bus. They have a tendency to visit many places that are unicursal and continuous routes. In the future, the increase of Japanese tourists can be expected in the district by construction of new Shinkansen lines. However, if the Taiwanese use a sightseeing bus during the first five years the number will increase. Using a sightseeing bus keeps a lid on costs for groups compared to a trip by train and it is convenient. It is necessary to improve the traffic infrastructure for sightseeing buses on increasing groups of tourists from Asia and to establish a high value-added service. It is also essential to always survey the trends of Taiwanese tourists.

\section{Acknowledgements}

The authors would like to thank the Research and Statistics Division of Kanazawa City, the Tourism Division of Takayama City, Tateyama-KurobeKanko Corp., Service Industries Division of Shirakawa Village and the Tourist Association of Unazuki Spa for provision of accurate information.

\section{References}

[1] Yomiurishinbun, Morning edition, 12 April 2006 (in Japanese).

[2] Hokkokushinbun, Morning edition, 26 April 2006 (in Japanese).

[3] White Paper on Tourism, National Land and Transportation Ministry, 2004 (in Japanese). 
[4] Handbook for JNTO attraction of inbound tourists 2005/2006, Japan National Tourism Organization (JNTO), 2006 (in Japanese).

[5] International Tourism View in 2004, Asia-Pacific Tourism Exchange Center, 2006 (in Japanese).

[6] Monthly Report Taiwan Tourism, Taiwan Tourist Association, 1 November 2005 (in Japanese).

[7] Travel Data in 2005, Tourism Division of Takayama City, 2006 (in Japanese).

[8] Koshin-Junrei, Tourism Division of Shirakawa Village, 2005 (in Japanese).

[9] Yui, Shirakawa Village, 2005 (in Japanese).

[10] Sawada, A., Mo, M., Shimbo, T. \& Oyabu, T., Trend of Aged Tourist and Application of Tourism Resources in Nanao City. Kanko-to-Joho (Tourism Informatics), 2, pp.41-48, 2006. 